\title{
Posterior Reversibl Ensefalopati Sendromu: Sistemik Lupus Eritematozuslu Hastalarda Görülen Nadir ve Acil Bir Klinik Antite
}

\author{
Posterior Reversible Encephalopathy Syndrome: A Rare and Urgent Clinical \\ Entity in Patients with Systemic Lupus Erythematosus
}

Gözde Yıldırım ÇETIN

Kahramanmaraş Sütçü İmam Üniversitesi Tip Fakültesi Hastanesi Romatoloji BD, Kahramanmaraş

Geliş Tarihi:27.09.2019 Kabul Tarihi:04.11.2019 DOI: 10.17517/ksutfd.626090

Özet

Posterior reversibl ensefalopati sendromu (PRES), hipertansiyon, baş ağrısı, konfüzyon, nöbet, görme değişiklikleri ile karakterize posterior serebral dolaşımda (beyin sapı, serebellum, parietal lob, temporal lob, oksipital lob ve posterior ön lob dahil olabilen) vazojenik ödem şeklinde görülen klinik ve radyolojik bir antitedir. PRES’li hastaların yaklaşık yarısında sistemik lupus eritematozus (SLE) gibi otoimmün bir hastalık öyküsü vardır. PRES gelişen SLE hastalarında erken tanı ve tedavi önemlidir. Bu sayede çoğunlukla selim seyirli bir hastalık erkenden tanınmış olur ve gereksiz tetkiklerin önüne geçilebilir.

Anahtar Kelimeler: Posterior Reversibl Ensefalopati Sendromu, Sistemik Lupus Eritematozuslu, Acil

\begin{abstract}
PRES is a clinical and radiological entity occurs as a vasogenic edema in the posterior cerebral circulation (including brain stem, cerebellum, parietal lobe, temporal lobe, occipital lobe and posterior anterior lobe) characterized by hypertension, headache, confusion, seizures, visual changes. Approximately half of th patients with PRES have a history of autoimmune diseases such as systemic lupus erythematosus (SLE). Early diagnosis and treatment of PRES in patients with SLE are crucial. In this way, usually a benign disease is recognized early and unnecessary examinations can be prevented.
\end{abstract}

Keywords: Posterior Reversible Encephalopathy Syndrome, Systemic Lupus Erythematosus, Urgent

Yazışma Adresi: Gözde Yıldırım Çetin, Kahramanmaraş Sütçü İmam Üniversitesi Tıp Fakültesi Hastanesi Romatoloji BD, Kahramanmaraş Tlf:05053946753 Mail: gozdeyildirimcetin@gmail.com

ORCID No: 0000-0001-9680-7535 


\section{GİRIŞ}

Posterior reversibl ensefalopati sendromu (PRES) ilk kez Hinchey ve arkadaşları tarafından 1996 yılında tanımlanmıştır. PRES, hipertansiyon, başağrısı, konfüzyon, nöbet, görme değişiklikleri ile karakterize posterior serebral dolaşımda (beyin sap1, serebellum, parietal lob, temporal lob, oksipital lob ve posterior ön lob dahil olabilen) vazojenik ödem şeklinde görülen klinik ve radyolojik bir antitedir (1). PRES’li hastaların yaklaşık yarısında sistemik lupus eritematozus (SLE), Behçet hastalığ1, anti-nötrofil sitoplazmik antikor ilişkili vaskülit ve romatoid artrit gibi bir otoimmün hastalık öyküsü vardır (2).

1996-2019 yılları arasında PubMed'de sistemik lupus eritematozus ve posterior reversibl ensefalopati sendromu beraber tarandığında çok sayıda vaka bildirimi ve vaka serisi bulunmaktadır. Bu yayınlar incelendiğinde hastaların çoğunun daha genç, önceden hipertansiyon öyküsü olan, aktif hastalık döneminde, özellikle böbrek tutulumu olan hastalar olduğu bildirilmiştir. 2019'da yapılan bir vaka-kontrol çalışmasında 7059 SLE'li hastanın 29'unda otuz PRES epizodu tanımlanmış ve prevelans \%0,43 olarak bulunmuştur (2).

PRES, SLE'li hastalarda çok nadir görülen bir durum olduğu için bu sendromu tanımak ve takibini yapmak hastadan hastaya değişir. SLE’li hastaların \%50'sinde nörolojik semptom ve bulgular görülebilmesine rağmen PRES, SLE ile ilişkili 19 nöropsikiyatrik sendrom sınıflamasına alınmamıştir (3).

\section{PRES patogenezi:}

PRES patogenezi halen tam olarak anlaşılamamıştır. En sık kabul edilen teori serebral kan akımında disregülayon ve hipertansiyonun sebep olduğu vazojenik ödem ve kan-beyin bariyerindeki bozulmadır. Kan basıncında değişiklik olduğunda serebral dolaşımda vazokonstrüksiyon veya vazodilatasyon ortaya çıkar ve kan basıncı normal aralıkta tutulmaya çalışılır, bu sayede serebral kan akımında belirgin değişiklik olmaz. Tansiyon yüksekliği belirli bir eşik değeri geçince vazokonstrüksiyon yeterli gelmez ve kan-beyin bariyeri aşılır sonuç olarak beyin parankimine eritrositler, makro-moleküller ve sıvı geçer. Beyin korteksi ödeme direnç gösterebilir ancak kan-beyin bariyeri aşılması ile ödem subkortikal alana yayılmaktadır. Sempatik sistem ve vazokonstriksiyon cevabı posterior dolaşımda, anteriora göre daha zayıftır ve ödem çoğunlukla posterior alanda görülür (4).

SLE'de yüksek oranda renal disfonksiyon olduğu düşünülürse, bunun sonucunda ortaya çıkan sıvı retansiyonu ve sebep olduğu hipertansiyon SLE'de görülen PRES sendromunun en sık sebebini oluşturur. Bu hipotez renal disfonksiyon ve hipertansiyonun SLE'li PRES hastalarında bağımsız risk faktörü olmasının bulunması ile desteklenmiştir. Aynı zamanda eklampsi ve kalp yetmezliğinin yine PRES için bağımsız risk faktörleri olduğu bilinmektedir. Eklampsi ve kalp yetmezliği olan hastalarda yüksek kan volümü ve ciddi hipertansiyon vardır (5). Yine yüksek doz kortikosteroid ile tedavi ve kan transfüzyonu sonrasında gelişen yüksek kan basıncı PRES’i kısmen açıklar (6). Hipertansiyon ilişkili epilepsi ve vazojenik serebral ödem tablolarında olduğu gibi çoğu hastada serebral perfüzyondaki otoregülasyon bozukluğu tipik PRES'deki mekanizmayı açıklayabilir ama normal ya da düşük kan basıncı olan kişilerde de PRES sendromu görüldüğü unutulmamalıdır.

SLE'li hastalarda farklı mekanizmalar ön plana çıkar, en önemlisi de endotelyal disfonksiyondur. Aktif SLE hastalarında tedavi sırasında kullanılan yüksek doz kortikosteroidler anormal vasküler tonusu arttırabilir ve siklofosfamidin vasküler endotel üzerindeki sitotoksik etkisi altta yatan mekanizma olarak kabul edilebilir. Bununla birlikte, PRES’li SLE hastaları aktif dönemde oldukları ve birçok ilaç aldığı için bu iki ilacın PRES gelişimindeki rolü için daha ileri çalışmalara ihtiyaç vardır (7).

Sitotoksik tedaviler vasküler entotelyum üzerine direkt toksisite yapabilir, kapiller sızdırmalara sebep olur, kan-beyin bariyerinde hasara ve aksonal şişmeye sebep olur; bu durum daha sonra vazojenik ödeme neden olur (8). Normotansif veya hafif hipertansif bireylerde ortaya çıkar ve bu ilaçların toksik olmayan dozlarında da görülebilir. Endotelyal disfonksiyon teorisinde tümör nekroz faktör alfa (TNF- $\alpha$ ), interlökin (IL)-1 ve IL-6 gibi proinflamatuar sitokinlerin rolü ön plana çıar. Bu sitokinler vasküler endotelyal growth faktör (VEGF) üretimini indükler ve bu sayede kan-beyin bariyeri permeabilitesi artar. VEGF internal organ tutulumu olan ve hastalık aktivite indeksi yüksek olan hastalarda yüksek bulunur. Yapılan yeni bir çalışmada bu teoriyi destekler şekilde, yüksek SLEDAI-N skorları, kalp yetmezliği ve nefrit, PRES için bağımsız risk faktörü olarak bulunmuştur. IL-1 ve TNF- $\alpha$ interselüler adezyon molekül-1 ekspresyonun indükler, bu molekül lökositler ve endotelyal hücre aktivasyonunu sağlayan markerlar ile etkileşime girer (9). Endotelyal disfonksiyon SLE patogenezinde rol oynayan diğer yollar ile birlikte hareket eder. SLE sistemik aktivasyonu inflamatuar hücrelerde TNF- $\alpha$ ve interferon- $\otimes$ salınımını artırır, bu sitokinler intrakranial damarlardaki endotelyal hücrelerden ve astrositlerden vazojenik serebral ödeme sebep olan nitrik oksit salınımını uyarır (10).

Üremi, sepsis, hipomagnezemi ve diğer metabolik bozukluklarda vasküler endotelyal fonksiyon etkilenerek PRES ortaya çıkabilir.

\section{PRES'in klinik bulguları:}

Analjeziklere cevap vermeyen, lokalize olmayan, orta şiddetliden çok şiddetliye kadar değişebilen baş ağrısı görülür. Kan basıncı normale dönünce çoğunlukla baş ağrısı düzelir (11). Genel halsizlik ve ya letarji ve konfüzyon, nadiren stupor veya komaya kadar değişen bilinç değişikliği ortaya çıkar (12). Görme değişiklikleri sıklıkla vardır ve normal bir fundoskopik muayeneye rağmen, görme keskinliği, görme alanı ve ışık algısını önemli ölçüde etkileyebilir. Akut kortikal 
körlük PRES’li hastalar arasında yaygın bir bulgudur. Auralar veya görsel halüsinasyonlar nadiren görülür (13).

PRES'de nöbetler sıklıkla sendromun ortaya çıkış bulgusudur. Diğer epileptik nöbetlere benzer şekilde beyinde etkilenen bölgeye göre nöbet çeşidi değişir. Genellikle oksipital ve parietal loplar etkilendiği için fokal nöbet şeklinde başlayan jeneralize tonik-klonik nöbet görülür. Bir kez ya da tekrarlar şeklinde olabilir, oksipital lob etkilendiyse görme değişiklikleri eşlik eder (14). Derin tendon refleksleri canlı olabilir ve Babinski pozitifliği mevcut olabilir (11). Nadiren güçsüzlük ve ekstremitelerde koordinasyon bozukluğu görülebilir. Diğer fokal nörolojik bozukluklar nadirdir.

\section{PRES'de görüntüleme:}

PRES, MR'da görülebilen posterior dolaşım disfonksiyonu ile karakterize bir sendromdur. Nörogörüntüleme PRES tanısı için esastır, en iyi şekilde MR ile gösterilebilir. Tipik bulgular posterior serebral hemisferlerde, özellikle parieto-oksipital bölgelerde bilateral beyaz cevher ödemidir. Kranial MR'da FLAIR ve T2 ağırlıklı görüntülerde posterior serebral bölgelerde, bilateral kortikal-subkortikal hiperintens lezyonlar ile karakterizedir (15). Ancak anterior dolaşımın etkilenmesi de nadir değildir. Kortikal ve infratentorial tutulum veya anterior dolaşım etkilenmesi PRES'li hastaların \%56’sında gösterilmiştir (16). Yaygın vazojenik ödem bazı serilerdeki daha kötü klinik sonuçlarla ilişkilendirilmiştir, ancak klinik bulguların şiddeti ile ilişkili değildir (17).

\section{PRES'de takip ve tedavi:}

SLE'ye sekonder gelişen PRES'de tedavi etiyolojiye yönelik yapılmalıdır. Hipertansiyon sonucu oluşan PRES için etkili tedavi kan basıncının agresif kontrolü ve zamanında anti epileptik ilaç kullanımı ile olur. Serberal ödemdeki artışı önlemek için sistolik kan basıncını aşamalı olarak düşürmek önemlidir. Hızlı düzeltme önerilmez özellikle gebe hastalarda uteroplasental kan akımını azaltacağı için daha dikkatli olunmalıdır. İntravenöz nikardipin (5-15 mg/saat) veya labetalol (2-3 mg/dk) birinci aşamada tercih edilecek ilaçlardır. Nitrogliserinden kaçınılmalıdır çünkü serebral vazodilatasyon yapar (18).

Antiepileptik tedavi intravenöz verilmeli ve ilaç seçimi hastanın status epileptikus durumuna göre seçilmelidir. Status epileptikus nörolojik acil bir durumdur, rekürren epileptik nöbetler devam eder ve nöbet aralarında tam düzelme olmaz (19). Benzodiazepinler (lorazepam veya diazepam) birinci basamak ilaç olarak tercih edilmeli, tedaviden fayda elde etmek için hemen başlanmalıdır. Nöbetler intermittan devam ederse veya status epileptikus benzodiazepinlere dirençli ise ikinci basamak ilaç olarak fenitoin veya fosfenitoin tercih edilebilir. Fosfenitoin, fenitoin ile karşılaştırıldı ̆̆ında daha az mukokutanöz yan etki ile ilişkilidir ve seçim mevcut olduğunda tercih edilir. Üçüncü sıradaki ilaçlar barbitürat, fenobarbital veya anestezik propofolü içerir (20).
Eğer PRES yüksek doz kortikosteroid ve immünsüpresif ilaç kullanımı sonucu ortaya çıkarsa, hemen bu tedaviler kesilmelidir $(1,21)$. Ancak yüksek doz immünsüpresif tedavi gereken SLE hastaları genellikle ciddi aktif hastalık evresinde olan hastalardır. Çoğu hastada böyle ciddi bir ataktan sonra immünsüpresif tedaviyi devam etmek ya da ilaç dozlarını artırmak gerekebilir. Son zamanda yapılan bir çalışmada ilaç dozları artırılmasına rağmen PRES sendromu geri dönüşlü olmuştur (2).

Elektrolit bozuklukları, aşırı sıvı yüklenmesi, üremi ve sepsis gibi komorbid koşullar, PRES'li hastalarda, hastalığın ortaya çıkmasına ve prognoza katkı sağladığı için, bu durumların tedavisi önerilmektedir. Trombotik trombositopenik purpura sırasında ortaya çıkan PRES'de plazmaferez veya intravenöz immünoglobulin etkili bulunmuştur. PRES hastaları deksametazon ile tedavi edilmiştir ancak yüksek tansiyon, sıvı yüklenmesi ve elektrolit bozukluğu riski olduğu için ayrıca yüksek doz steroid tedavisinin PRES gelişimi ile ilişkili olması nedeniyle, bu tedavide çok dikkatli olunması önerilir (22). PRES adından da anlaşılacağı üzere reversibl bir sendromudur ve hastaların \%75-90'1 2-8 gün içerisinde tamamıla düzelir. Ancak son zamanlarda PRES'in tamamiyla düzelmeden ilerlediğini gösteren vaka raporları da mevcuttur.

Ciddi vakalarda, serebral otoregülasyonun yeterli olmamasının reaktif fokal vazokonstriksiyona yol açtığı, bunun sonucunda lokal hipoperfüzyon, sitotoksik ödem ve beyin enfarktüsüne yol açtı̆̆ı ileri sürülmüştür. Aynı zamanda PRES'de nadir görülen beyin enfarktüslerinin, vazojenik ödemin kütle etkisinden dolayı mikro dolaşımın sıkıştırılmasından kaynaklanması da mümkündür (22). Tanı ve tedavide gecikme ölüm ya da irreversibl nörolojik semptomlara sebep olabilir. Legriel ve arkadaşlarının yaptığı çalışmada PRES vakaları takip edilmiş ve olaydan 90 gün sonra hastaların \%44'ünde devam eden ciddi fonksiyon kaybı gözlenmiştir (23).

SLE'li hastalardaki mortalite, çalışmalarda farklı raporlanmıştır. Geniş katılımcı sayısı olan iki çalışmada yüksek mortalite oranları dikkat çeker [\%29,17 (7/24 vaka) ve \%26,9 (7/26 vaka)] $(3,24)$.Yüksek mortalite aktif hastalıkla ilişkili olabilir çünkü yüksek SLEDAI değerleri SLE'li hastalardaki PRES için bağımsız risk faktörüdür (2). Yine başka bir çalışmada PRES atağı sırasında SLEDAI-N $\geq 18$ olan hastalarda mortalite riski anlamlı yüksek bulunmuştur (3).

Sonuç olarak PRES sendromu gelişen SLE hastalarında erken tanı ve tedavi önemlidir. Bu sayede çoğunlukla selim seyirli bir hastalık erkenden tanınmış olur ve gereksiz tetkiklerin önüne geçilebilir. 


\section{KAYNAKLAR}

1. Hinchey J, Chaves C, Appignani B, Breen J, Pao L, Wang A et al. A reversible posterior leukoencephalopathy syndrome. N Engl J Med 1996 Feb 22;334(8):494-500. doi: 10.1056/ NEJM199602223340803.

2. Cui HW, Lei RY, Zhang SG, Han LS, Zhang BA. Clinical features, outcomes and risk factors for posterior reversible encephalopathy syndrome in systemic lupus erythematosus: a case-control study. Lupus 2019 Jul;28(8):961-969. doi: 10.1177/0961203319856416. Epub 2019 Jun 17.

3. Damrongpipatkul U, Oranratanachai K, Kasitanon N, Wuttiplakorn S, Louthrenoo W. Clinical Features, Outcome, and Associated Factors for Posterior Reversible Encephalopathy in Thai Patients With Systemic Lupus Erythematosus: A Case-Control Study. Clin Rhemumatol 2018 Mar;37(3):691-702. doi: 10.1007/ s10067-017-3892-2. Epub 2017 Nov 4.

4. Pande AR, Ando K, Ishikura R, Nagami Y, Takada Y, Wada A et al. Clinicoradiological Factors Influencing the Reversibility of Posterior Reversible Encephalopathy Syndrome: A Multicenter Study. Radiat Med 2006 Dec;24(10):659-68. doi: 10.1007/ s11604-006-0086-2.Epub 2006 Dec 25.

5. Dong XY, Bai CB, Nao JF. Clinical and radiological features of posterior reversible encephalopathy syndrome in patients with preeclampsia and eclampsia. Clin Radiol 2017 Oct;72(10):887895. doi: 10.1016/j.crad.2017.06.009

6. Jung SM, Moon SJ, Kwok SK, Ju JH, Park KS, Park SH et al Posterior reversible encephalopathy syndrome in Korean patients with systemic lupus erythematosus: Risk factors and clinical outcome. Lupus 2013 Aug;22(9):885-91. doi: 10.1177/0961203313496341.

7. Bertsias GK, Ioannidis JP, Aringer M, Boller E, Bomberdieri S, Bruce IN et al. EULAR recommendations for the management of systemic lupus erythematosus with neuropsychiatric manifestations: report of a task force of the EULAR standing committee for clinical affairs. Ann Rheum Dis. 2017 Mar;76(3):476485. doi: 10.1136/annrheumdis-2016-209770.

8. Hanly JG, McCurdy G, Fougere L, Douglas JA, Thompson K. Neuropsychiatric events in systemic lupus erythematosus: attribution and clinical significance. J Rheumatol 2004 Nov;31(11):2156-62.

9. Dardis C, Craciun R, Schell R. Posterior reversible encephalopathy syndrome in thesetting of COPD: Proposed pathogenesis. Med Hypotheses 2013 Feb;80(2):197-200. doi: 10.1016/j. mehy.2012.11.028.

10. Lee SC, Dickson DW, Liu W, Brosnan CF. Induction of nitric oxidesynthaseactivity in humanastrocytesby interleukin-1 beta and interferon-gamma. J Neuroimmunol 1993 Jul;46(1-2):19 24. doi: 10.1016/0165-5728(93)90229-r.

11. Stott V, Hurrell M, Anderson T. Reversible posterior leukoencephalopathy syndrome: A misnomer reviewed. Intern Med J 2005 Feb;35(2):83-90. doi: 10.1111/j.1445-5994.2004.00750.x.

12. Van Diest D, Van Goethem JWM, Vercruyssen A, Jadoul C, Cras P. Posterior reversible encephalopathy and Guillain-Barre syndrome in a single patient: Coincidence or causative relation? Clinical Neurol Neurosurg 2007 Jan;109(1):58-62.

13. Garg, R. Posterior leukoencephalopathy syndrome. Postgrad Med J 2001 Jan; 77(903):24-28

14. Adams H, Adams R, Zoppo GD, Goldstein LB; Stroke Council of the American Heart Association, The American Stroke Association. Guidelines for the early management of patients with ischemic stroke: 2005 guidelines update, a scientific statement from the stroke council of the American Heart Association and the American Stroke Association. Stroke 2005 Apr;36(4):91623. doi: 10.1161/01.STR.0000163257.66207.2d.

15. Covarrubias DJ, Luetmer PH, Campeau NG. Posterior reversible encephalopathy syndrome: prognostic utility of quantitative diffusion-weighted MR images. AJNR Am J Neuroradiol 2002; Jun-July 23(6):1038-48.

16. Chou MC, Lai PH, Yeh LR, Li JY, Yuan MK, Liang HL, et al. Posterior reversible encephalopathy syndrome: Magnetic resonance imaging and diffusion weighted imaging in 12 cases. Kaohsiung J Med Sci 2004 Aug;20(8):381-8. doi: 10.1016/S1607551X(09)70174-3.

17. Schwartz RB, Jones KM, Kalina P, Bajakian RL, Mantello MT, Grade B, et al. Hypertensive encephalopathy: findings on CT, MR imaging, and SPECT imaging in 14 cases. AJR Am J Roentgenol 1992 Aug;159 (2):379-83.

18. Servillo G, Bifulco F, De Robertis E, Piazza O, Striano P, Tortora F,et al. Posterior reversible encephalopathy syndrome in intensive care medicine. Intensive Care Med 2007 Feb;33(2):230-6. doi: 10.1007/s00134-006-0459-0

19. Robakis T, Hirsch L. Literature review, case report, and expert discussion for prolonged refractory status epilepticus. Neurocrit Care 2006;4(1):35-46. doi: 10.1385/NCC:4:1:035.

20. Marchetti A, Magar R, Fischer J, Sloan E, Fischer P. A pharmacoeconomic evaluation of intravenous fosphenytoin (Cerebyx) versus intravenous phenytoin (Dilantin) in hospital emergency departments. Clin Ther1996 Sept-Oct;18(5):953-66. doi: 10.1016/s0149-2918(96)80051-8.

21. Fugate JE, Rabinstein AA. Posterior reversible encephalopathy syndrome: Clinical and radiological manifestations, pathophysiology, and outstanding questions. Lancet Neurol 2015;14(9):914-925. doi: 10.1016/S1474-4422(15)00111-8.

22. Mukherjee P, McKinstry RC. Reversible posterior leukoencephalopathy syndrome: evaluation with diffusion-tensor MR imaging. Radiology 2001 Jun;219(3):756-65. doi: 10.1148/radiology.219.3.r01jn48756.

23. Legriel S, Schraub O, Azoulay E, Hantson P, Magelhaes E, Coquet I, et al. Determinants of recovery from severe posterior reversible encephalopathy syndrome. PLoS One 2012;7(9):e44534. doi: 10.1371/journal.pone.0044534.

24. Lai CC, Chen WS, Chang YS, Wang SH, Huang CJ, Guo WY, et al. Clinical features and outcomes of posterior reversible encephalopathy syndrome in patients with systemic lupus erythematosus. Arthritis Care Res (Hoboken) 2013; Nov;65(11):1766-74. doi: 10.1002/acr.22047. 